\title{
RUNX3 Inhibits Cell Proliferation and Induces Apoptosis by TGF- $\beta$-Dependent and -Independent Mechanisms in Human Colon Carcinoma Cells
}

\author{
Dan-dan Tong ${ }^{a}$ Ying Jiang ${ }^{b}$ Ming Lic Dan Kong ${ }^{e}$ Xiang-nin Meng ${ }^{c}$ \\ Yu-zhen Zhao ${ }^{c}$ Yan Jin ${ }^{c}$ Jing Bai ${ }^{c}$ Song-bin Fuc Jing-shu Geng ${ }^{d}$ \\ ${ }^{a}$ Department of Pathology, ${ }^{b}$ Second Affiliated Hospital and ' Laboratory of Medical Genetics, Harbin Medical \\ University, and d Department of Pathology, Tumor Hospital, Harbin Medical University, Harbin, China; \\ eSchool of Medical Sciences, Kanazawa University, Kanazawa, Japan
}

Key Words

Apoptosis $\cdot$ Bim $\cdot$ Growth inhibition $\cdot \mathrm{RUNX} 3 \cdot \mathrm{Smad} \cdot \mathrm{TGF}-\beta$

\begin{abstract}
Background: Genes involved in the TGF- $\beta$ signaling pathway are often altered in several types of cancers. The TGF- $\beta$ resistant human colon cancer cell line HT-29 has inactivated T $\beta$ RII and deficient expression of RUNX3 and Smad4, which are involved in the TGF- $\beta$ signaling pathway. Methods: Western blot and immunocytochemistry were performed to confirm gene expression, the MTT assay to detect cell growth, flow cytometry to investigate the cell cycle and the TUNEL to detect cell apoptosis. Results: In the absence of TGF- $\beta$, Bim was upregulated, cell growth was inhibited and apoptosis was induced. TGF- $\beta$ treatment did not affect RUNX3 expression; however, the increase in Bim expression was significant and time dependent. Interestingly, Smad4 but not Smad2/3 was also upregulated upon exposure to TGF- $\beta$. This was not the case after TGF- $\beta$ treatment of parent HT-29 cells. As expected, TGF- $\beta$ further inhibited cell growth and induced apoptosis in HT-29/RUNX3+ cells. Conclusion: Our data demonstrate that RUNX3 is involved in TGF- $\beta$-dependent and -independent cell growth inhibition and apoptosis induction pathways.

Copyright $\odot 2009$ S. Karger AG, Basel
\end{abstract}

\section{Introduction}

The transforming growth factor (TGF)- $\beta$ signaling pathway modulates many cellular functions, including cellular proliferation, differentiation and apoptosis [1-4]. However, the ability of TGF- $\beta$ to induce apoptosis seems to vary markedly depending on the cell type or experimental conditions. It has been reported that the Bcl-2-interacting mediator of cell death (Bim) is crucial for the TGF- $\beta$ apoptosis pathway [5]. Also, the transcriptional control of Smad3-Smad4 signaling is necessary to upregulate Bim expression in the TGF- $\beta$-induced apoptosis [6]. Other reports indicate that RUNX3 is also involved in TGF- $\beta$-mediated growth inhibition and apoptosis [6-8]. RUNX3 deficiency results in TGF- $\beta$-resistant SEG-1 cell proliferation and apoptosis, although cells still possess TGF- $\beta$-mediated receptor-regulated Smads (R-Smads) signaling [9]. RUNX3 expression can induce TGF- $\beta$-induced Smad3/4-mediated transcriptional activity [9]. Enforced RUNX3 expression leads to cell growth inhibition and apoptosis [10].

RUNX3 is also responsible for transcriptional upregulation of Bim in TGF- $\beta$-induced apoptosis [11]. Similarly, restoration of RUNX3 expression led to Bim upregulation and increased apoptosis in the absence of TGF- $\beta$ or

\section{KARGER}

Fax +4161306 1234 E-Mail karger@karger.ch www.karger.com

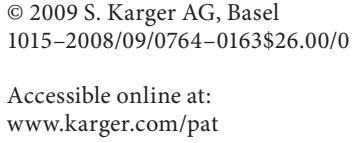

Dr. Jing-shu Geng

Department of Pathology

Tumor Hospital, Harbin Medical University

Harbin 150081 (China)

Tel. +86 4518629 8232, Fax +86 4518629 8232, E-Mail jeangeng2004@yahoo.com.cn 
the presence of Smads; TGF- $\beta$ stimulation did not enhance RUNX3-induced Bim upregulation and apoptosis [12]. However, RUNX3 sensitized cells to the proapoptotic effects of TGF- $\beta$ [12].

These reports [1-12] are often contradictory and the exact molecular regulation of TGF- $\beta$-dependent tumor suppressor function is therefore still unclear. The TGF- $\beta$ signaling pathway plays an important role in tumor suppressor mechanisms and has been studied in various human gastrointestinal tumors, including colon, gastric and pancreatic cancers [13]. HT-29, a human colon cancer cell line, has an inactivated form of TRRII, and this causes an impaired TGF- $\beta$-Smad signaling pathway $[14,15]$. Recently, RUNX3 and Smad4 expression were also found to be deficient or not present in HT-29 cell lines [16, 17].

In the present study, RUNX3 gene expression was recovered in HT-29/RUNX3+ cell lines using a RUNX3 expression plasmid. Then, cell growth and apoptosis of HT-29/RUNX3 + were assessed in the presence of TGF- $\beta$. The TGF- $\beta$-signal-related proteins $\operatorname{Smad} 2 / 3, \operatorname{Smad} 4$ and Bim were detected by Western blot and immunohistochemistry analyses. Subsequently, overexpression of RUNX3, Smad2/3, Smad4 and Bim protein was investigated in order to clarify the signaling pathways of cell growth and apoptosis.

\section{Materials and Methods}

\section{Cell Line and Cell Culture}

The human colon cancer cell line HT-29 was provided by the Laboratory of Medical Genetics, Harbin Medical University (Harbin, China), and cultured in RPMI 1640 (Sigma, St. Louis, Mo., USA) supplemented with $10 \%$ (vol/vol) fetal bovine serum (Gibco, Gaithersburg, Md., USA) at $37^{\circ} \mathrm{C}$ with $5 \% \mathrm{CO}_{2}$.

\section{Cell Transfection}

The expression plasmid containing the complementary DNA (cDNA) for human RUNX3 was kindly provided by Dr. S. Hiebert (Vanderbilt University, Nashville, Tenn., USA) [12]. For transfection, RUNX3 cDNAs were subcloned into the pcDNA3.1+ vector. HT-29 cells were transfected, using a mixture of Lipofectamine 2000 (Invitrogen) and Plus Reagent to generate stable transfectants, which were selected in the presence of $0.35 \mathrm{mg} / \mathrm{ml} \mathrm{G} 418$ (Invitrogen). Independent clones that stably expressed RUNX3 were identified by Western blot analysis using an anti-RUNX3 monoclonal antibody (Active Motif, Carlsbad, Calif., USA).

\section{Western Blot Assays}

The HT-29/RUNX3+ cell lines were cultured in the absence of $10 \mathrm{ng} / \mathrm{ml}$ TGF- $\beta_{1}$ (PeproTech, London, UK) for $0,3,6,24$ or $48 \mathrm{~h}$ in serum-free medium. Then, the medium was removed and the cells were washed with ice-cold PBS three times and lysed with appropriate RIPA buffer ( $\mathrm{NaCl} 150 \mathrm{mM}$, Triton X-100 1\%, deoxycholate $0.5 \%$, SDS $0.1 \%$ and Tris base $50 \mathrm{~mm}$ ) and protease in- hibitor. The cells were then scraped, placed on ice for $1 \mathrm{~h}$ and disrupted using three bursts of ultrasound. The solution was then centrifuged at $16,000 \mathrm{~g}$ for $15 \mathrm{~min}$ at $4^{\circ} \mathrm{C}$, the supernatant was divided into aliquots and the total protein was measured using the Bradford assay.

Equal amounts of protein extractions of HT-29/RUNX3+ were separated by $10 \%$ SDS-PAGE; the separated proteins were transferred onto polyvinylidene fluoride membranes and incubated with blocking buffer consisting of TBS-T (Tris-buffered saline, $0.01 \%$ Tween 20 ) and $5 \%$ nonfat dry milk. Individual membranes were washed and incubated with RUNX3 monoclonal antibody (Active Motif), Smad4 monoclonal antibody (Santa Cruz, Santa Cruz, Calif., USA), phosphorylated Smad2/3 polyclonal antibody (Santa Cruz) or Bim polyclonal antibody (sc-11425; Santa Cruz) for $1 \mathrm{~h}$ at room temperature. After a further three washes with TBS-T, the membranes were incubated with secondary antibody conjugated with horseradish peroxidase (1:2,000 dilution) for $1 \mathrm{~h}$ at room temperature, further washed and then incubated for 1 min with an enhanced chemiluminescence detection system (ECL-Plus; Amersham Pharmacia Biotech, Uppsala, Sweden).

\section{Immunocytochemistry}

Cells (parent HT-29 cells and HT-29/RUNX3+) were cultured in the absence of $10 \mathrm{ng} / \mathrm{ml} \mathrm{TGF}-\beta$ for $48 \mathrm{~h}$ in serum-free medium. The cells were fixed with $4 \%$ paraformaldehyde for $15 \mathrm{~min}$ and then further treated with $0.1 \%$ Triton X-100 for 15 min to permeabilize the cells. Cells were incubated with primary antibodies (anti-RUNX3, anti-Smad 4 and anti-Bim) at $4^{\circ} \mathrm{C}$ overnight and subsequently with horseradish-peroxidase-conjugated secondary antibody for $1 \mathrm{~h}$ at room temperature. Finally, the slides were developed with DAB using a kit (Zhongshan Goldenbridge Biotechnology, Beijing, China).

\section{MTT}

Cells were seeded in 96-well plates and sequential cell counting was performed every $24 \mathrm{~h}$ over a period of 6 days. Cells were treated with $10 \mathrm{ng} / \mathrm{ml}$ TGF- $\beta$ for $48 \mathrm{~h}$ after which cell growth was assessed. Aliquots $(20 \mathrm{ml})$ of $5 \mathrm{mg} / \mathrm{ml}$ sterile MTT were added to the cells and incubated for $4 \mathrm{~h}$ at $37^{\circ} \mathrm{C}$. After aspiration of the medium, $150 \mathrm{ml}$ DMSO (Sigma) were added and mixed, and absorbance was determined using a microplate reader (BioRad, Hercules, Calif., USA) at a test wavelength of $492 \mathrm{~nm}$.

\section{Flow Cytometry}

Cells were cultured in the absence of $10 \mathrm{ng} / \mathrm{ml}$ TGF- $\beta_{1}$ (Peprotech) in serum-free medium for $48 \mathrm{~h}$. Cells were then washed quickly with PBS twice, fixed in ethanol, stored at $4{ }^{\circ} \mathrm{C}$ overnight, resuspended in propidium iodide staining buffer ( $50 \mathrm{~g} / \mathrm{l}$ propidium iodide and $15 \mathrm{~g} / \mathrm{l}$ RNase) and incubated for $20 \mathrm{~min}$ in the dark at room temperature. DNA content was evaluated by flow-cytometric analysis (Cycle Test Plus DNA reagent kit; BD Biosciences, San Jose, Calif., USA). The experiments were repeated three times. Each experiment had a control group. Every group had two parallels.

Terminal-Deoxynucleotidyl Transferase-Mediated Nick End Labeling (TUNEL)

Cells were seeded in 24-well plates with coverslips $25 \mathrm{~mm}$ in diameter on each well. Cells were treated with $10 \mathrm{ng} / \mathrm{ml}$ of TGF- $\beta_{1}$ for $48 \mathrm{~h}$ in serum-free medium. Then, cells were washed twice 
Fig. 1. Restored RUNX3 inhibits cell growth of human colon HT-29 cells. a HT29 cells were plated in complete growth medium, incubated for $24 \mathrm{~h}$ and transfected with RUNX3 cDNA or the empty vector. Whole-cell lysates of 5 transfected cell clones were separated by SDS-PAGE and analyzed by Western blot using antiRUNX3 or anti-GAPDH monoclonal antibodies. b Whole-cell lysates of HT29 cells and stable transfected HT-29/ RUNX3+ cells (clone 3, a) were separated by SDS-PAGE and overexpression of RUNX3 was achieved. c Growth of HT-29 and HT-29/RUNX3+ cells was detected using the MTT assay. Growth of HT-29/ RUNX3+ cells was found to be inhibited. $\mathrm{OD}=$ Optical density. $\mathbf{d}$ SDS-PAGE and Western blot analysis of RUNX3, PSmad2/3, Smad4, Bim or GAPDH were done in HT-29/RUNX3+ cells. Results indicate that Bim was upregulated.

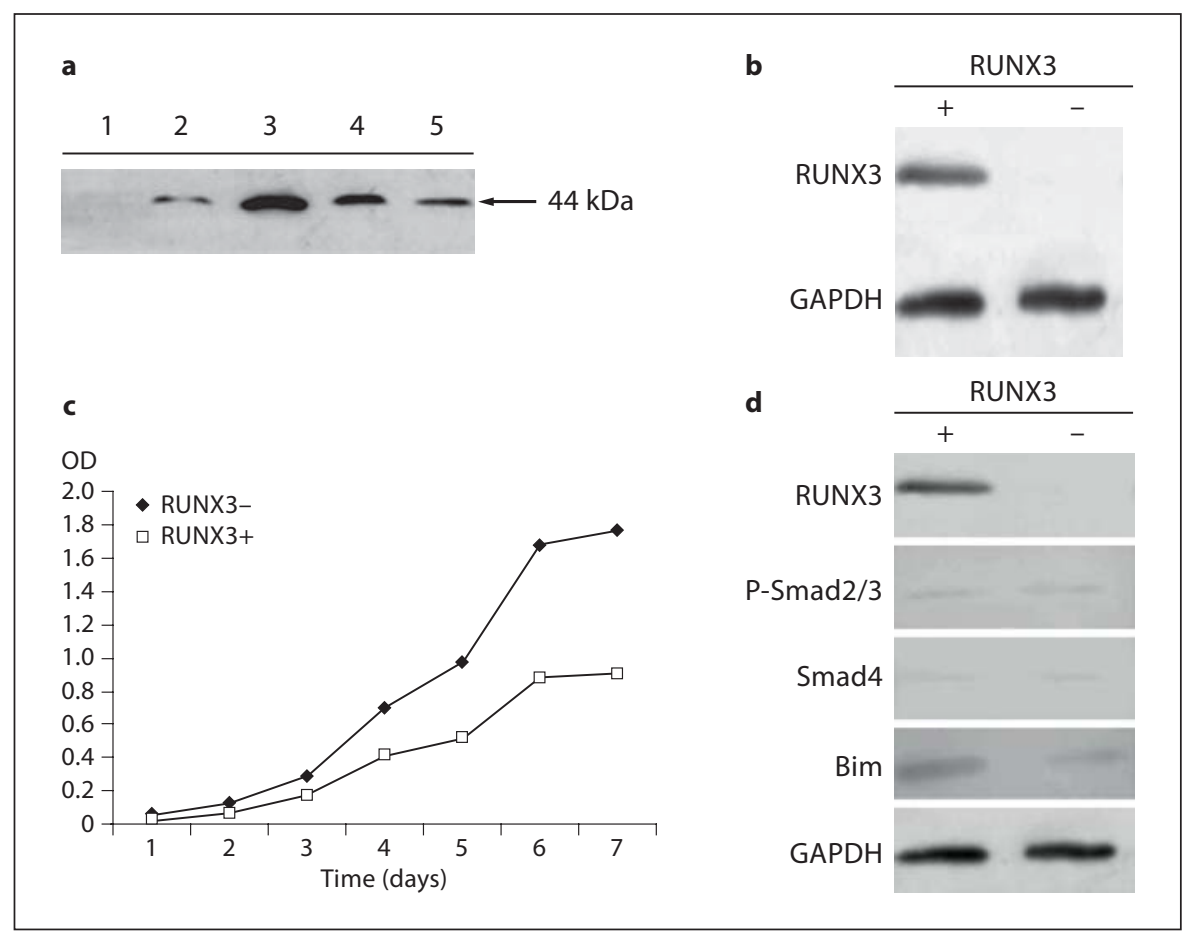

quickly with PBS and immediately fixed for $30 \mathrm{~min}$ in $4 \%$ paraformaldehyde prepared in PBS. The experiment was performed according to the In Situ Cell Death Detection Kit instructions (Roche, Indianapolis, Ind., USA), and positive cells per low-power field were counted. The experiments were repeated three times.

\section{Results}

\section{Inhibition of Cell Growth by Re-Introduction of the RUNX3 Gene}

A series of genes are involved in the TGF- $\beta$ tumor suppressor signaling pathways. Although inactivated T $\beta$ RII and Smad 4 were associated with impaired TGF- $\beta$-Smad signaling in HT-29, RUNX3 was also a target for this impairment [14-17]. RUNX3 was hypermethylated and its transcripts were not detected in HT-29 cells [17]. We transfected RUNX3 into HT-29 human colon carcinoma cells in order to investigate the role of RUNX3 in TGF- $\beta$ tumor suppressor signaling pathways. Overexpression of RUNX3 protein in transfected HT-29/RUNX3+ cells is demonstrated in figurela, b. Growth of HT-29/RUNX3+ cells was compared with that of parent HT-29 cells using the MTT method. The growth curve demonstrates that re-introduction of the RUNX3 gene inhibited cell growth. A difference in cell growth was measurable after 2 days of culture (fig. 1c).

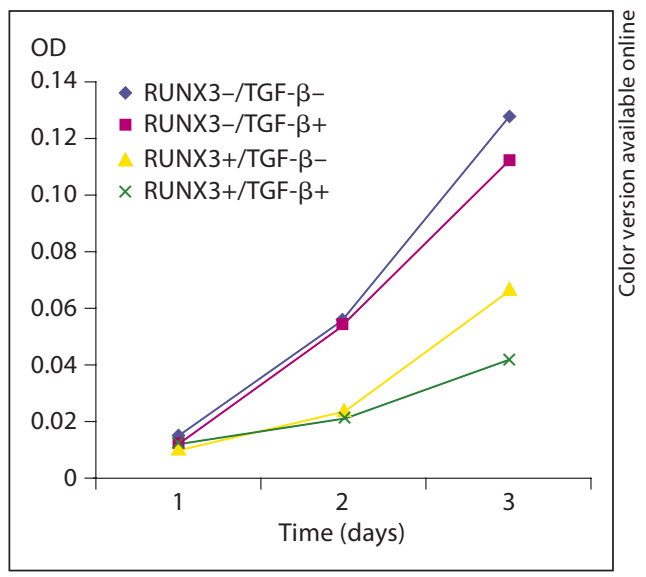

Fig. 2. Cell growth inhibition by RUNX3 and enhanced inhibition by TGF- $\beta$ treatment. Parent HT-29 and HT-29/RUNX3+ cells were cultured in the absence or presence of $10 \mathrm{ng} / \mathrm{ml} \mathrm{TGF}-\beta$ for 3 days in serum-free medium. During the 3 days, cell growth was measured by optical density (OD) values using the MTT assay. Results showed that growth of HT-29/RUNX3+ cells was inhibited, and this effect was enhanced by TGF- $\beta$ treatment.

\section{Re-Introduction of RUNX3 Leads to Overexpression of Bim in HT-29 Cells}

Previous reports have implicated Bim in mediating the apoptotic effect of RUNX3 in the TGF- $\beta$ signaling 


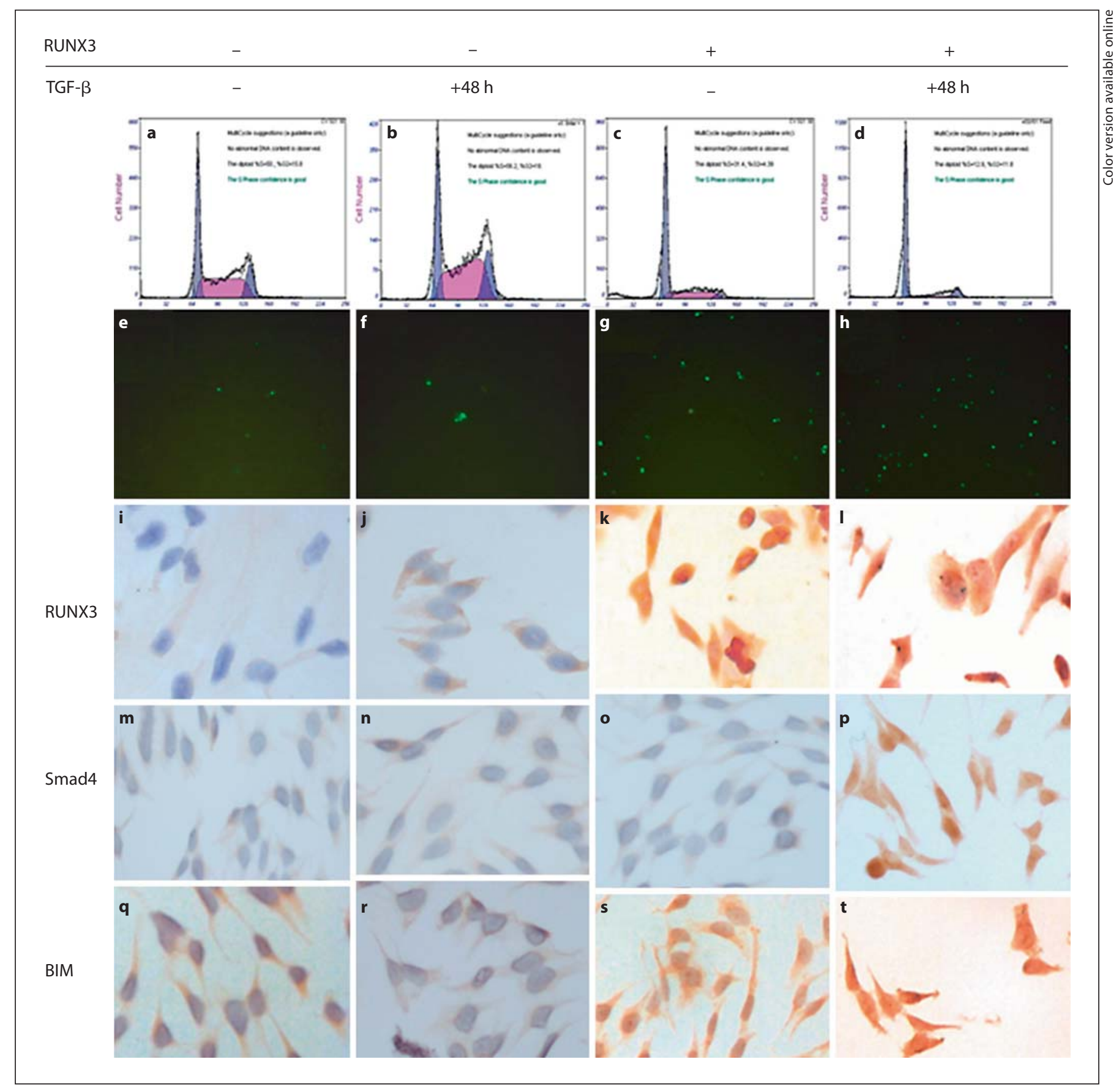

Fig. 3. Overexpression of RUNX3 induces cell cycle arrest and apoptosis. Parent HT-29 cells and HT-29/RUNX3+ cells were cultured in the absence or presence of $10 \mathrm{ng} / \mathrm{ml} \mathrm{TGF}-\beta$ in serum-free medium. Flow cytometry was performed $48 \mathrm{~h}$ after TGF- $\beta$ treatment. Results show cell cycle arrest at $\mathrm{G}_{0} / \mathrm{G}_{1}$ in HT-29/RUNX3+ cells. This effect was enhanced by treatment with TGF- $\beta$ (a-d). Apoptosis was determined by TUNEL staining for fluorescence microscopy. Results demonstrate that TGF- $\beta$ induces apoptosis in both parent HT-29 and HT-29/RUNX3+ cells. This effect is en- hanced by TGF- $\beta$ treatment (e-h, fluorescence, original magnification $\times 100$ ). Imunocytochemical analysis of RUNX3, Bim or Smad 4 was performed 48 h after TGF- $\beta$ treatment. Results show that RUNX3 expression is restored in HT-29/RUNX3+ cells and no effect of TGF- $\beta$ treatment was noted. RUNX3 was found to induce Bim expression and this effect was enhanced in the presence of TGF- $\beta$ treatment. TGF- $\beta$ induced Smad 4 expression in HT-29/RUNX3 + cells but not in parent HT-29 cells (i-t, original magnification $\times 200)$. 
Fig. 4. TGF- $\beta$ induces Smad 4 and Bim upregulation after overexpression of RUNX3. HT-29/RUNX3+ (a) and parent HT-29 (b) cells were cultured in the absence or presence of $10 \mathrm{ng} / \mathrm{ml} \mathrm{TGF-} \beta$ for $0,3,6,24$ or $48 \mathrm{~h}$ in serum-free medium. Western blot was performed and antibodies to $\mathrm{P}$ Smad2/3, Smad4, Bim and GAPDH were used. Results show that RUNX3 expression was restored in HT-29/RUNX3+ cells, which was not affected by TGF treatment. Also, Smad2/3 expression was not regulated by RUNX3 or TGF- $\beta$. TGF- $\beta$ induced Smad4 expression in a time-dependent manner in HT-29/RUNX3+ cells but not in HT-29/RUNX3 - cells. RUNX3 induced Bim expression and this was enhanced in the presence of TGF- $\beta$ treatment.

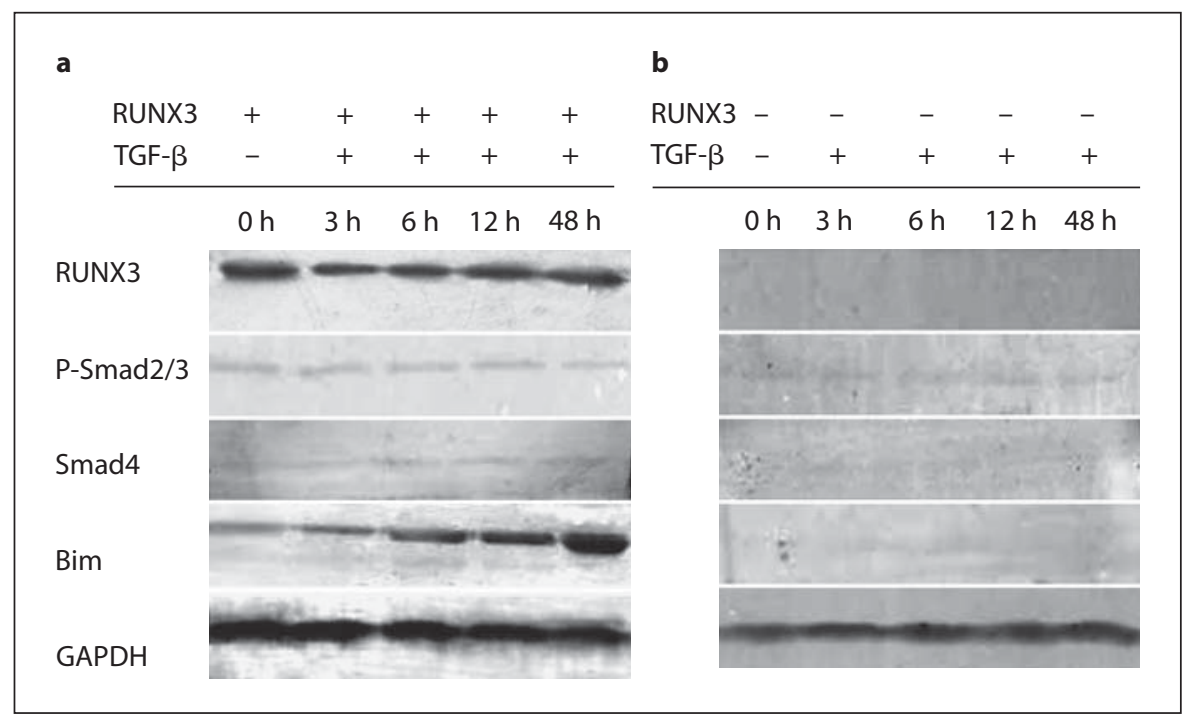

pathway. Apoptosis was induced by RUNX3 in the absence of TGF- $\beta$. To investigate signaling pathways in HT-29 cells, Bim expression was measured in HT-29/ RUNX3+ and untransfected HT-29 cells. Re-introduction of the RUNX3 gene led to a concomitant overexpression of Bim. In these experiments, phosphorylated Smad $2 / 3$ and Smad 4 were expressed at low levels and no regulation was observed in response to RUNX3 transfection (fig. 1d).

RUNX3 Induces $G_{0} / G_{1}$-Phase Cell Cycle Arrest and Apoptosis in HT-29 Cells, Which Can Be Enhanced by TGF- $\beta$

According to previous results, HT-29 cells are not responsive to exogenous TGF- $\beta$ [15-19]. These cells do not show a decrease in clonogenicity or proliferation induced by TGF- $\beta_{1}$ or TGF- $\beta_{2}$ [19]. RUNX3 has been shown to be an important target for TGF- $\beta$ signaling and may be related to TGF- $\beta$ pathway inactivation in HT-29 cells. To verify this finding, HT-29/RUNX3+ cells were cultured in the absence of TGF- $\beta$ and cell growth was measured every $24 \mathrm{~h}$ over a period of 3 days. TGF- $\beta$ was found to be able to further slow down cell growth in HT-29/ RUNX3+ cells (fig. 2). Flow-cytometric analysis of DNA profiles showed that introduction of RUNX3 in HT-29 cells arrested the cells in the $G_{0} / G_{1}$ phase of the cell cycle. While the percentage of parent HT-29 cells in $G_{0} / G_{1}$ was $34 \%$, in HT-29/RUNX3+ cells the percentage was increased to $64 \%$. The percentage of cells in S phase decreased from 49 to $31 \%$, and the percentage of cells in $\mathrm{G}_{2} / \mathrm{M}$ phase decreased from 16 to $4 \%$ (fig. $3 \mathrm{a}, \mathrm{c}$ ). After
TGF- $\beta$ treatment, $G_{0} / G_{1}$ cell cycle arrest was enhanced in HT-29/RUNX3 + cells from 64 to $75 \%$. The percentage of cells in S phase further decreased to $13 \%$ (fig. 3c, d). To investigate whether these phenomena coincide with induction of apoptosis, TUNEL assays were performed. The results showed that re-introduction of RUNX3 in HT-29 cells leads to cell apoptosis, which was further increased after TGF- $\beta$ exposure (fig. $3 \mathrm{e}-\mathrm{g}$ ).

\section{RUNX3, Smad4 and Bim Are Located in the}

Cytoplasm and Nucleus of HT-29/RUNX3+Cells

Bim was found in the cytoplasm and nucleus of HT29/RUNX3 + cells when RUNX3 expression was recovered (fig. 3k, 1). When parent HT-29 cells and HT-29/ RUNX3+ cells were incubated with TGF- $\beta$ for $48 \mathrm{~h}$, immunohistochemistry showed that RUNX3, Smad4 and Bim localize in the cytoplasm and nucleus of HT-29/ RUNX3+ cells (fig. 3i-t). TGF- $\beta$ upregulated the expression of Bim and Smad4 in HT-29/RUNX3+ cells, but not in parent HT-29 cells (fig. 3i-t).

\section{RUNX3-Mediated TGF- $\beta$-Induced Expression of \\ Smad4 and Bim in HT-29/RUNX3+ Cells}

Western blot was performed in parent cells and HT29/RUNX3 + cells incubated with TGF- $\beta$ for $0,3,6,12$ or $48 \mathrm{~h}$. The results show that in HT-29/RUNX3+ cells, TGF- $\beta$ induced time-dependent Bim and Smad 4 expression, but there was no change in $\mathrm{P}-\mathrm{Smad} 2 / 3$ expression levels (fig. 4a). By contrast, there were no changes in the expression levels of these genes in parent cells incubated with TGF- $\beta$ (fig. 4 b). 


\section{Discussion}

The TGF- $\beta$-Smads signaling pathway is considered to be the canonical pathway and has been extensively characterized: TGF- $\beta$ initiates the signaling pathway by activating specific type II (TRRII) and type I (TßRI) receptors on the cell surface [20]; the receptor then phosphorylates R-Smads (Smad2 and Smad3). Phosphorylated R-Smads associate with Smad4 and move into the nucleus. In addition, RUNX proteins are considered important for TGF- $\beta$ signaling [8]. The RUNX family of transcription factors has been shown to physically interact with TGF- $\beta$-activated Smads and mediate TGF- $\beta$ signaling [21]. RUNX family members share numerous important biological functions with members of the TGF- $\beta$ superfamily [22]. Having a tumor suppressor role, TGF- $\beta$ signaling pathways are disrupted in many cancers. The type II TGF- $\beta$ receptor is inactivated in colon and gastric cancers. In addition, (i) Smad 2 mutations have been found in colon cancers; (ii) Smad4 is inactivated in colon and pancreatic cancers [20,23], and (iii) no RUNX3 expression was found in gastric and colon cancers [24, 25].

HT-29, a human colon cancer cell line, has an altered type II TGF- $\beta$ receptor, and lack of expression of Smad4 and RUNX3 can lead to inactivation of the TGF- $\beta$ apoptosis pathway in this cell line [14-17]. Similarly, several studies have revealed that HT-29 cells are resistant to the TGF- $\beta$ pathway. In the present study, we restored RUNX3 expression in HT-29 cells by transfection of a RUNX3 expression plasmid and found that cell growth was inhibited and apoptosis was induced in the absence of TGF- $\beta$ stimulation.

However, in esophageal adenocarcinoma cells, expression of RUNX3 in the absence of TGF- $\beta$ treatment did not induce cell apoptosis [9]. We then investigated the TGF- $\beta$-pathway-related genes and found that Bim was upregulated following RUNX3 expression. Bim is a Bcl-2 family member which induces apoptosis by counteracting the function of anti-apoptotic members of the Bcl-2 family [26]. The first evidence that Bim expression is increased by addition of TGF- $\beta$ was found in WEHI $231 \mathrm{~B}$ lymphocytes, and it was also suggested that $S$ mad3 plays a role in mediating Bim expression and apoptosis [5]. The RUNX3-dependent induction of Bim by TGF- $\beta$ has been observed in gastric cells [10]. Other studies have provided evidence that upregulation of Bim, under the transcriptional control of Smad3-Smad4 signaling, is crucial to TGF- $\beta$-induced apoptosis in Hep3B cells [6]. However, levels of Smad2/3 and Smad4 expression did not change with RUNX3 overexpression in HT-29 cells, which fur- ther demonstrates that Bim upregulation occurs in the absence of TGF- $\beta$ treatment. It has been reported that RUNX3 cooperates with FoxO3a/FKHRL1 to activate Bim expression and induces apoptosis independently of TGF- $\beta$ [12]. Together with our results, this may demonstrate that there is a RUNX3-Bim pathway that can associate with genes other than the TGF- $\beta$-related genes.

Furthermore, TGF- $\beta$ treatment led to cell growth inhibition and increased apoptosis. The TGF- $\beta$-pathwayrelated genes were investigated, and Smad 4 and Bim were shown to be upregulated by TGF- $\beta$ stimulation. $\operatorname{Smad} 2 / 3$ expression was not effected. RUNX3 expression was not changed by the presence of TGF- $\beta$. The TGF- $\beta$ apoptosis pathway involves several genes. Smad 3 mediates TGF- $\beta$ induced Bim expression and apoptosis in WEHI 231 cells [5]. Through RNAi, Smad3 and Smad4 have been shown to be the main mediators of TGF- $\beta$-induced apoptosis and be under the transcriptional control of Smad3-Smad4 signaling, and that Bim is crucial for TGF- $\beta$-induced apoptosis in Hep3B cells [6]. Bim is a positive target of RUNX3 in TGF- $\beta$-induced apoptosis in gastric epithelial cells [10]. RUNX3 knockout cells do not respond to TGF$\beta$-induced maturation inhibition, even though the ex-

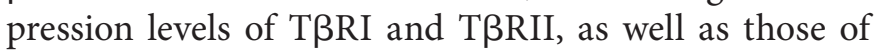
Smad2 and Smad3, were unaffected [27]. SEG-1 cell growth is resistant to TGF- $\beta$ and, although Smad2 signaling is activated by TGF- $\beta$, TGF- $\beta$ lacks Smad-mediated transcriptional activity in SEG-1 cells. Transfection of expression vectors for RUNX3 could upregulate Smad3/4 in response to TGF- $\beta$ [9]. In HT-29 cells, we found that RUNX3 is crucial for TGF- $\beta$-induced upregulation of Smad4 and Bim expression, but RUNX3 had no effect on Smad4 expression in the absence of TGF- $\beta$.

In conclusion, we found that RUNX3 can upregulate the expression of Bim and induce cell cycle arrest and apoptosis. Also, with TGF- $\beta$ stimulation, RUNX3 not only induced Bim expression but also upregulated the level of Smad4 expression, which further increased cell cycle arrest and apoptosis. However, the mechanisms by which RUNX3-Bim and TGF- $\beta$-RUNX3-Smad4/Bim exert these effects are not yet clear and, therefore, further studies are needed.

\section{Acknowledgment}

This research was supported by the Postdoctoral Science Foundation of China (code number: LRB-03-162). 


\section{References}

1 Massague J: TGF-beta signal transduction. Annu Rev Biochem 1998;67:753-791.

-2 Piek E, Heldin CH, Ten Dijke P: Specificity, diversity, and regulation in TGF-beta superfamily signaling. FASEB J 1999;13:21052124.

-3 Wrana JL: Regulation of Smad activity. Cell 2000;100:189-192.

4 Massague J, Chen YG: Controlling TGF-beta signaling. Genes Dev 2000;14:627-644.

5 Wildey GM, Patil S, Howe PH: Smad3 potentiates transforming growth factor beta (TGFbeta)-induced apoptosis and expression of the BH3-only protein Bim in WEHI $231 \mathrm{~B}$ lymphocytes. J Biol Chem 2003;278:1806918077.

6 Yu J, Zhang L, Chen A, Xiang G, Wang Y, Wu J, Mitchelson K, Cheng J, Zhou Y: Identification of the gene transcription and apoptosis mediated by TGF-beta-Smad2/3-Smad4 signaling. J Cell Physiol 2008;215:422-433.

$\checkmark 7$ Li QL, Ito K, Sakakura C, Fukamachi H, Inoue K, Chi XZ, Lee KY, Nomura S, Lee CW, Han SB, Kim HM, Kim WJ, Yamamoto H, Yamashita N, Yano T, Ikeda T, Itohara S, Inazawa J, Abe T, Hagiwara A, Yamagishi $H$, Ooe A, Kaneda A, Sugimura T, Ushijima T, Bae SC, Ito Y: Causal relationship between the loss of RUNX3 expression and gastric cancer. Cell 2002;109:113-124.

$>8$ Ito Y, Miyazono K: RUNX transcription factors as key targets of TGF-beta superfamily signaling. Curr Opin Genet Dev 2003;13:4347.

-9 Torquati A, O’Rear L, Longobardi L, Spagnoli A, Richards WO, Daniel Beauchamp R: RUNX3 inhibits cell proliferation and induces apoptosis by reinstating transforming growth factor beta responsiveness in esophageal adenocarcinoma cells. Surgery 2004; 136:310-316.

$\checkmark 10$ Wei D, Gong W, Oh SC, Li Q, Kim WD, Wang L, Le X, Yao J, Wu TT, Huang S, Xie K: Loss of RUNX3 expression significantly affects the clinical outcome of gastric cancer patients and its restoration causes drastic suppression of tumor growth and metastasis. Cancer Res 2005;65:4809-4816.
11 Yano T, Ito K, Fukamachi H, Chi XZ, Wee $\mathrm{HJ}$, Inoue K, Ida H, Bouillet P, Strasser A, Bae SC, Ito Y: The RUNX3 tumor suppressor upregulates Bim in gastric epithelial cells undergoing transforming growth factor betainduced apoptosis. Mol Cell Biol 2006;26: 4474-4488.

-12 Yamamura Y, Lee WL, Inoue K, Ida H, Ito Y: RUNX3 cooperates with FoxO3a to induce apoptosis in gastric cancer cells. J Biol Chem 2006;281:5267-5276.

13 Markowitz SD, Roberts AB: Tumor suppressor activity of the TGF-beta pathway in human cancers. Cytokine Growth Factor Rev 1996;7:93-102.

14 Winesett MP, Ramsey GW, Barnard JA: Type ii TGF(beta) receptor expression in intestinal cell lines and in the intestinal tract. Carcinogenesis 1996;17:989-995.

15 Ijichi H, Ikenoue T, Kato N, Mitsuno Y, Togo G, Kato J, Kanai F, Shiratori Y, Omata M: Systematic analysis of the TGF-beta-Smad signaling pathway in gastrointestinal cancer cells. Biochem Biophys Res Commun 2001; 289:350-357.

16 Goel A, Arnold CN, Tassone P, Chang DK, Niedzwiecki D, Dowell JM, Wasserman L, Compton C, Mayer RJ, Bertagnolli MM, Boland CR: Epigenetic inactivation of RUNX3 in microsatellite unstable sporadic colon cancers. Int J Cancer 2004;112:754-759.

-17 Shiou SR, Singh AB, Moorthy K, Datta PK, Washington MK, Beauchamp RD, Dhawan $\mathrm{P}: \mathrm{Smad} 4$ regulates claudin-1 expression in a transforming growth factor-beta-independent manner in colon cancer cells. Cancer Res 2007;67:1571-1579.

18 Schroy P, Rifkin J, Coffey RJ, Winawer S, Friedman E: Role of transforming growth factor beta 1 in induction of colon carcinoma differentiation by hexamethylene bisacetamide. Cancer Res 1990;50:261-265.
19 Suardet L, Gaide AC, Calmes JM, Sordat B, Givel JC, Eliason JF, Odartchenko N: Responsiveness of three newly established human colorectal cancer cell lines to transforming growth factors beta 1 and beta 2 . Cancer Res 1992;52:3705-3712.

20 Massague J, Blain SW, Lo RS: TGF $\beta$ signaling in growth control, cancer, and heritable disorders. Cell 2000;103:295-309.

21 Hanai J, Chen LF, Kanno T, Ohtani-Fujita N, Kim WY, Guo WH, Imamura T, Ishidou Y, Fukuchi M, Shi MJ, Stavnezer J, Kawabata M, Miyazono K, Ito Y: Interaction and functional cooperation of $\mathrm{PEBP} 2 / \mathrm{CBF}$ with Smads. Synergistic induction of the immunoglobulin germline $\mathrm{C} \alpha$ promoter. J Biol Chem 1999;274:31577-31582.

22 Lund AH, van Lohuizen M: RUNX: a trilogy of cancer genes. Cancer Cell 2002;1:213215.

23 Derynck R, Akhurst RJ, Balmain A: TGFbeta signaling in tumor suppression and cancer progression. Nat Genet 2001;29:117129.

24 Ito K, Liu Q, Salto-Tellez M, Yano T, Tada K, Ida $\mathrm{H}$, Huang $\mathrm{C}$, Shah N, Inoue M, Rajnakova A, Hiong KC, Peh BK, Han HC, Ito T, Teh M, Yeoh KG, Ito Y: RUNX3, a novel tumor suppressor, is frequently inactivated in gastric cancer by protein mislocalization. Cancer Res 2005;65:7743-7750

25 Kim TY, Lee HJ, Hwang KS, Lee M, Kim JW, Bang YJ, Kang GH: Methylation of RUNX3 in various types of human cancers and premalignant stages of gastric carcinoma. Lab Invest 2004;84:479-484.

26 Huang DC, Strasser A: BH3-only proteins essential initiators of apoptotic cell death. Cell 2000;103:839-842.

27 Fainaru O, Woolf E, Lotem J, Yarmus M, Brenner O, Goldenberg D, Negreanu V, Bernstein Y, Levanon D, Jung S, Groner Y: Runx3 regulates mouse TGF-beta-mediated dendritic cell function and its absence results in airway inflammation. EMBO J 2004; 23:969-979. 